\title{
My Journey of Life to a Pediatric Dentist
}

\author{
Bandana Koirala ${ }^{1}$ \\ ${ }^{1}$ Professor, Department of Pedodontics and Preventive Dentistry, College of Dental Surgery, \\ B.P. Koirala Institute of Health Sciences, Dharan, Nepal.
}

Have you ever wondered what it feels like to be a Pediatric Dentist?.OK friends, today I am going to take you to my journey of life, a beautiful and a memorable one - that which treads the path of love, empathy and patience, a path full of hope, very less comprehended but one that leads to immense happiness and contentment in life. Yes! Dear ones, that's MY journey which landed me into the world of ecstasy, fulfillment and compassion; where thinking vanishes, doing is natural and feeling is ALL that counts.

After my BDS, I was a workaholic kind, passionate to sharpen my skills newly acquired, and merge deep into the meaning of dentistry and its unfoldments. Working with children was something I had a knack-of since my UG days, where I used to welcome my Pedo posting in contrast to what I found my friends dreaded. Lively and innocent, these beautiful creations of the Supreme are no less a wonder onto themselves. Understanding them and devoting oneself into their world, opens up an entirely new chapter of life which otherwise buries unexplored. Enjoying these little magicians, which is a suitable synonym to these benevolent lives full of buoyancy and vibrant.

Little did I know, when I joined B.P. Koirala Institute of Health Sciences immediately after my graduation, that I was about to step into one such journey of exploring the real beauty that life had in store of my experiences. This was how, surprisingly, I was presented with an opportunity to choose this field which I still feel proud of. Starting days of my residency possessed a new realm in all the aspects of

\section{Correspondence}

Dr. Bandana Koirala

Professor, Department of Pedodontics and Preventive

Dentistry, BPKIHS, Dharan, Nepal

E-mail: drkbandu@yahoo.com

\section{Citation}

Koirala B. My Journey of Life to a Pediatric Dentist. J Nepalese Assoc Pediatr Dent. 2020;1(1):44-7. my life where I found myself in the stark opposite of where I had completed majority of my higher education i.e., South India. New to everything, it was only these mini physical beings with their existence similar-to or even larger than the adults, that seemed familiar to me in King George's Medical College (KGMC), North India. Moments when I used to see my colleagues or seniors struggling with any child, something stirred in me and I used to spring-up to reach to them, to make them comply for the treatment they were brought for. Well! It was this that led me to even choose my thesis topic on "The comparative evaluation of newer sedatives in conscious sedation" esp., for the ones who many a times were left unattended or abandoned.

Time kept rolling on, life had presented me with multiple avenues during my whole residency, where I had one more such being to nurture - my own child, as I struggled to carve smiles and spirit to the little ones who visited me every single day in quite an overwhelming number. I kept on moving - undertaking my journey, understanding the one I borne sole responsibility for, and the ones who visited me when in need. Lovely became the atmosphere, when I immersed myself in healing them and didn't even realize growing and maturing silently and gradually in their presence. Finally, when I joined back to my mother Institute, the real journey then begun, the unfoldments kept growing and I immersed myself in their world of healing once again, but through a different perspective.

Passionate about my profession, never did I hesitate to inspire minds for pursuing this field of dentistry. Since there were no pediatric dentists from Nepal when I came back, the task of healing surmounted, it was then, we began the first residency program at BPKIHS in 2011. Reaching and learning paralleled in this journey, where I found myself now completely evolved. Seeing many hearts and souls emerging in my chosen path fills me with joy and immense gratitude. 
I do not know what did I do in my previous life-times to have gotten this beautiful life today, being a part of this role-play from the Director and Creator of the script called LIFE but I love every moment and opportunity beholding this role; my life, my journey can never end or perish 'cause I hold these little ones' hands and cherish their smiles in my heart. I love to love them, to share MY part for hearing theirs, and move on together in this journey - MY Journey of being a Pediatric Dentist fulfills the unspoken, the unexpressed.

Well friends-words are no limit in sketching my views for you to comprehend... just try to feel my expressions which I poured heart-out in front of you unaltered; and to THOSE who ever have a dilemma for this journey... Oh! Come-on, it's NOW or Never, don't you want to rise-up in your eyes, savouring the richness of experiences and laughter that this journey awaits to present you??

AMEN... A heart spoken out.

Conflict of Interest: None 